\begin{abstract}
Iranica
Abstracta Iranica Revue bibliographique pour le domaine irano-aryen

Volume 37-38-39 | 2018

Comptes rendus des publications de 2014-2016
\end{abstract}

\title{
Michael Jung (ed). The Wall Paintings of the Great Mosque of Isffahān
}

\section{Viola Allegranzi}

\section{(2) OpenEdition}

\section{Édition électronique}

URL : http://journals.openedition.org/abstractairanica/43283

DOI : 10.4000/abstractairanica.43283

ISBN : 1961-960X

ISSN : 1961-960X

Éditeur :

CNRS (UMR 7528 Mondes iraniens et indiens), Éditions de l'IFRI

Référence électronique

Viola Allegranzi, « Michael Jung (ed). The Wall Paintings of the Great Mosque of Ișfahān », Abstracta

Iranica [En ligne], Volume 37-38-39 | 2018, document 25, mis en ligne le 30 décembre 2018, consulté le 10 décembre 2020. URL : http://journals.openedition.org/abstractairanica/43283 ; DOI : https:// doi.org/10.4000/abstractairanica.43283

Ce document a été généré automatiquement le 10 décembre 2020.

Tous droits réservés 


\title{
Michael Jung (ed). The Wall Paintings of the Great Mosque of Isfahān
}

\author{
Viola Allegranzi
}

\section{RÉFÉRENCE}

Michael Jung (ed), avec des contributions de: A. Altieri, P. Cornale, F. Frezzato, C.

Seccaroni. The Wall Paintings of the Great Mosque of Ișfahān. Firenze: Nardini Editore, 2016, 131 p., 141 ill., (Arte e Restauro/Casi studio), ISBN : 978-88-404-0435-6

1 L'ouvrage présente des recherches récemment accomplies sur l'ensemble des peintures murales relevées dans la Grande mosquée d'Ispahan. Ces enquêtes s'inscrivent dans un projet plus large, consacré à la reprise de l'étude des matériaux collectés dans la mosquée pendant les campagnes de fouille et de restauration italiennes (1970-1978, dir. U. Scerrato et E. Galderi).

2 Le corpus de peintures murales est réparti en deux sections selon un critère chronologique. Les peintures pré-seldjoukides incluent une quantité considérable de fragments provenant pour la plupart des fouilles dans le secteur sud de la mosquée, qui ont mis au jour une section du mur de la qibla et le mihrāa de la mosquée abbasside. Les peintures post-seldjoukides sont plus rares; elles ont été relevées in situ dans divers lieux du monument et correspondent à des expressions artistiques "populaires ", datant vraisemblablement de la période moderne (les seules peintures datées ont été réalisées à la période zand, vers la fin du XVIIIe siècle). L'analyse se concentre en particulier sur les témoignages pré-seldjoukides, datant probablement d'une période comprise entre la fin du VIIIe et la fin du Xe siècle : l'auteur offre une classification typologique des fragments, probablement issus d'un décor réalisé en plusieurs phases et comportant différents registres ornés de motifs épigraphiques, végétaux et géométriques. À cause de l'état fragmentaire des peintures et de la rareté des comparaisons stylistiques, des hypothèses de reconstitution des sujets peints ne sont avancées que dans un nombre limité de cas. 
3 Un long chapitre est enfin consacré aux résultats des analyses en laboratoire conduites sur un lot de fragments. Cette étude des matériaux et des techniques (composition et superposition des couches, pigments et dorure) enrichit considérablement l'analyse stylistique, et permet d'inscrire ce cycle de peintures murales dans la continuité de la tradition picturale de l'Asie centrale et de l'Iran préislamiques. Bien que la présentation du site et les questions chronologiques ne soient abordées que de manière sommaire, les données techniques et les nombreuses illustrations de ce volume permettent d'apprécier un corpus en grand partie inédit, qui compte parmi les plus anciens exemples de peinture murale de l'Iran islamique.

\section{AUTEURS}

VIOLA ALLEGRANZI

Université Sorbonne Nouvelle, Mondes iranien et indien, Paris 